\title{
Percent Recovered Over Dosing Interval Normalized by Weight
}

National Cancer Institute

\section{Source}

National Cancer Institute. Percent Recovered Over Dosing Interval Normalized by

Weight. NCl Thesaurus. Code C102389.

The percentage of the administered dose that is recovered from the specimen type specified in PPSPEC, between doses (TAU) divided by weight. 